\title{
MALEABILIDAD DEL COTO VEDADO EN LA PARTICIPAGIÓN CIUDADANA FRENTE A LA INSEGURIDAD PÚBLICA. LOS CASOS DE MÉXICO Y COLOMBIA*
}

\author{
MALLEABILITY OF FORBIDDEN LIMITS ON CITIZEN \\ PARTICIPATION REGARDING PUBLIC INSECUTIRI. \\ THE CASES OF MEXICO AND COLOMBIA
}

\section{Joaquín ORDÓÑEZ**}

\author{
Enrique URIBE ARZATE***
}

RESUMEN: Se aborda la relación entre los ABSTRACT: It addresses the relationship between the postulados de la teoría democrática del postulates of the democratic theory of the "coto veda"coto vedado" y la participación ciudadana $d o "$ (forbidden limits) and citizen participation in the frente a la inseguridad social, ya que dicha face of social insecurity, since this theory postulates teoría postula límites en el ejercicio de la democracia para la toma de decisiones, ya sean públicas o privadas, que deben ser realizadas teniendo en cuenta los límites infranqueables que constituyen el llamado "ámbito de negociación", constituido por aspectos inamovibles dado su carácter fundamental o axiológico. Esos límites y ese "ámbito" de lo negociable representan, contrario sensu, una posibilidad de tomar decisiones (y de actuar) por parte de agentes de la sociedad (generalmente ciudadanos, pero pueden también ser gobernantes) a efecto de corregir problemas sociales, como la inseguridad. El punto de certain limits in the exercise of democracy, for decision making, whether public or private, which must be made taking into account the insurmountable limits that constitute what has been called the "ámbito de negociación" (negotiating area) constituted by immovable aspects given their fundamental or axiological character. These limits and that "ámbito" (area) of the negotiable represent, on the contrary, a possibility to make decisions (and to act) on the part of certain agents of the society (generally citizens, but also governors) with the desirable effect to correct social problems such as insecurity. The point of discussion about the above is to determine if the "coto vedado"

* Artículo recibido el 14 de marzo de 2017 y aceptado para su publicación el 10 de mayo de 2020. Fue parte de la investigación CB/156846, financiada por el Conacyt y desarrollada por el Cuerpo Académico consolidado "Estudios Constitucionales" de la Facultad de Derecho de la Universidad Autónoma del Estado de México, y es producto de una estancia de investigación en Unisabaneta, Colombia, del lo. al 15 de febrero de 2017.

** ORCID: 0000-0002-6447-7188; doctor en derecho; investigador de tiempo completo, Facultad de Derecho, Universidad Autónoma del Estado de México, miembro del Sistema Nacional de Investigadores, nivel I. Correo electrónico: joaquin.o@me.com.

*** Doctor en derecho. Facultad de Derecho de la Universidad Autónoma del Estado de México. Correo electrónico: vercigtx@hotmail.com.

Boletín Mexicano de Derecho Comparado, nueva serie, año LII, núm. 157, enero-abril de 2020, pp. 243-270. 
discusión sobre lo anterior consiste en determinar si el coto vedado podría ser maleable o no y, en caso de serlo, determinar si en la realidad podría tener un impacto deseable en la solución de ciertos problemas sociales, para lo que se analizan los casos de inseguridad pública en México y Colombia. could be malleable or not and, if so, to determine if in reality it could have a desirable impact in the solution of certain social problems, for that, the cases of public insecurity in Mexico and Colombia are analyzed.

Keyreords: Democracy, Coto Vedado, Public Insecurity, Citizen Participation, México, Colombia.

Palabras clave: democracia, coto vedado, inseguridad pública, participación ciudadana, México, Colombia.

SUMARIO: I. Introducción. II. Coto vedado y ámbito de negociación: ¿flexibilidad o rigidez? III. Limites estatalesy ciudadanos: función del cotovedado. IV. Excepción a los límites de la participación ciudadana para el caso de la inseguridad pública. V. México y Colombia: casos de excepción al coto vedado. VI. Conclusión.

VII. Bibliografia.

\section{INTRODUCGIÓN}

La inseguridad pública es un problema de actualidad que sufren las sociedades incluso calificadas como democráticas; por ejemplo, la estadística en México muestra que dicho fenómeno se encuentra en un punto preocupante, ${ }^{1}$ aunado a que la participación ciudadana actualmente es de una intensidad muy baja, ${ }^{2}$ salvo los casos de organización para combatir la

1 A nivel nacional se registraron las siguientes tasas de incidencia delictiva de ocurrencia (número de eventos individuales de victimización delictiva reportados) por cada cien mil habitantes: a) año 2010/1, 30,535 eventos; b) año 2011/2, 29,200 eventos; c) año 2012/3, 35,139 eventos; d) año 2013/4, 41,563 eventos; e) año 2014, 41,655 eventos, y f) año 2015, 35,497 eventos; fuente: "Seguridad pública y justicia", Instituto Nacional de Estadística y Geografía (INEGI), disponible en: http://wrere.beta.inegi.org.mx/temas/incidencia/, consultado el 4 de marzo de 2017.

2 Tratándose de las elecciones presidenciales en 2000 y 2006, hubo una tendencia a la baja en cuanto a participación, mientras que en 2012 se observó un repunte, ya que la participación ciudadana alcanzó una tasa del $62.08 \%$, lo que representa un crecimiento de 3.85 puntos porcentuales por arriba de 2006; fuente: Instituto Federal Electoral (IFE) 2013, disponible en: EstudiosInvestigaciones/InvestigacionIFE/Estudio_Censal_Participacion_Ciudadana_2012.pdf.

Esta obra está bajo una Licencia Creative Commons

Atribución-NoComercial-SinDerivar 4.0 Internacional, IIJ-UNAM.

Boletín Mexicano de Derecho Comparado, núm. 157, enero-abril de 2020, pp. 243-270. 
delincuencia que han surgido. ${ }^{3}$ Lo anterior da pauta para la reflexión en torno de la participación ciudadana frente al problema grave de la inseguridad pública, considerando la teoría democrática del coto vedado, que postula la existencia de algunas "zonas" de decisión pública, unas permitidas y otras prohibidas, lo que aplica tanto para los gobernantes como para los gobernados. Significa que ni unos ni otros pueden tomar determinaciones o actuar en aspectos que inciden en la "zona" no permitida, lo que está determinado, de acuerdo con la teoría mencionada, por la cualidad de los aspectos sometidos a la decisión o a la actuación (ya sea del gobernante o del gobernado); por ello, algunos de esos aspectos relacionados con, por ejemplo, los derechos fundamentales, no deben ser sometidos a la voluntad decisoria y conductual de los agentes estatales mencionados. Los ciudadanos están limitados a actuar por sí mismos en los casos cuya actuación se reserva expresamente por la ley para los gobernantes (como la seguridad ciudadana); así, se puede hablar de una cierta "rigidez" en el diseño y estructura de esas "zonas" que constituyen el ámbito de negociación y el coto vedado, y no se podría hablar de prohibición en un determinado aspecto conductual o decisional en la vida pública estatal si ésta pudiera verse "modificada" por agentes externos a la propia prohibición. Sin embargo, en virtud de que el problema continúa y el Estado no ha logrado resolverlo de forma satisfactoria, lo que se postula en este trabajo es que el coto vedado ya ha sido realmente flexibilizado con la intención de resolver los problemas de seguridad pública. También se analiza la posibilidad de que tal coto pueda ser legítimamente modificable, que pueda ser maleable para erradicar o resolver tales problemas sociales. Desde luego, dicha flexibilidad debe ser revisada en términos del respeto a los derechos fundamentales, aspecto por demás discutible tratándose de las acciones gubernamentales o de la población.

En México ya ha habido manifestaciones de la ciudadanía en el sentido de tomar en sus manos la corrección de ciertos problemas sociales, como la delincuencia y la inseguridad ciudadana; lo anterior se puede evidenciar con las múltiples organizaciones ciudadanas, que van desde los

3 Ya en 2013 se daba la noticia de que grupos de autodefensa tomaron el control de 28 municipios en poder de las policías comunitarias; fuente: UniVisión Noticias. 2017. "Autodefensas en México se extienden: controlan 28 municipios de Michoacán", disponible en: http://wrere.univision.com/noticias/noticias-de-mexico/autodefensas-en-mexico-se-extiendencontrolan-28-municipios-de-michoacan. 
letreros en las entradas de comunidades y poblaciones ${ }^{4}$ hasta acciones tanto organizadas como espontáneas, ${ }^{5}$ lo cual ya es una flexibilización de esas "zonas" prohibidas, al ejecutar la ciudadanía - con base en sus propias decisiones - la solución de dichos problemas, y se trata, además, de un caso de participación del ciudadano llevado al extremo. En Colombia, la regulación de los estados de excepción, el estatuto antiterrorista y el derecho a la paz contenidos incluso en su Constitución, son casos de excepción al coto vedado regulados jurídicamente, lo cual constituye un caso paradigmático en comparativa con el mismo fenómeno ocurrido en México.

Los índices agravados de delincuencia significan que el Estado no ha logrado cumplir con uno de sus objetivos, consistente en proporcionar la seguridad ciudadana, lo que deja en un estado de indefensión a la población que, por estar esperando la solución gubernamental que no llega (o que llega deficiente), tiene que sufrir los embates de la delincuencia. Por ello, si se permitiera la maleabilidad del coto vedado en cierto grado, entonces la ciudadanía podría defender sus intereses y contrarrestar los efec-

4 En los cuales se pueden leer advertencias que se acercan mucho a amenazas, consistentes en prevenir a los delincuentes de que, para el caso de cometer algún delito o infracción y ser descubiertos por los vecinos, éstos tomarán represalias, que van desde la puesta a disposición de las autoridades (lo cual puede estar dentro del parámetro legal en términos de la legislación penal) hasta aplicar un castigo corporal en el momento en que tal fenómeno ocurra.

5 A este respecto, son variados los ejemplos que se pueden encontrar, en los que la comunidad o la ciudadanía han tomado el control de la seguridad pública; por ejemplo: policías comunitarias, sistemas de vigilancia privada y pagada por los mismos habitantes, agrupaciones vecinales apoyadas en mecanismos y estrategias de redes de autoprotección, como "Mi vecino me vigila", o algunos dispositivos de seguridad privados o de vigilancia privada autofinanciada, e incluso organismos no gubernamentales, como "México unido contra la delincuencia", o los grupos de autodefensa en Michoacán; también otros que ya se han hecho "justicia" por propia mano, como el caso del "Grupo de élite antirratas", en octubre de 2016 (banda así autodenominada que amputó las manos a siete presuntos ladrones, y que luego fueron abandonados con las manos mutiladas, en Tlaquepaque, Jalisco); fuente: El Mundo. Internacional, "Amputan las manos a siete ladrones en México", disponible en: http://wreweelmundo.es/internacional/2016/10/18/58061152468aebe413 8b4644.html; o el caso del "Vengador anónimo", en noviembre de 2016 (cuatro hombres que presuntamente asaltaban a usuarios de los camiones de pasajeros que se dirigían de San Mateo Atenco, Estado de México, a la Ciudad de México, fueron asesinados por un viajero al descender de la unidad que asaltaron); fuente: Excélsior. 2016. "Asesinados en La Marquesa asaltaban con frecuencia: transportistas", disponible en: http://wrere.excelsior.com. $m x /$ comunidad/2016/11/01/1125583.

Esta obra está bajo una Licencia Creative Commons

Atribución-NoComercial-SinDerivar 4.0 Internacional, IIJ-UNAM.

Boletín Mexicano de Derecho Comparado, núm. 157, enero-abril de 2020, pp. 243-270. 
tos de la delincuencia. La cuestión principal en este trabajo es la siguiente: ¿es legítimo que el coto vedado (y, por ende, el ámbito de negociación) se amplíe o se modifique (se considere maleable), con la finalidad de que la ciudadanía pueda intervenir con mayor intensidad, frecuencia y calidad en la erradicación o solución de la inseguridad ciudadana? Hipotéticamente, si consideramos al coto vedado y al ámbito de negociación como flexibles, entonces la ciudadanía podría intervenir con mayor intensidad y de forma más eficaz en la solución de la inseguridad ciudadana. Para lo anterior, se hace un análisis de lo que significa el coto vedado y el ámbito de negociación, cuestionando su rigidez y su posible flexibilidad, así como la revisión del papel que desempeña en cuanto a los límites estatales y ciudadanos. De ahí, teniendo como foco de atención los actuales fenómenos de violencia e inseguridad pública en México, se reflexiona sobre la posibilidad de excepción a los límites impuestos a la participación ciudadana en cuanto a su intervención en dicho fenómeno, por ser atribución específica del Estado; ello, tomando como parámetro los casos mexicano y colombiano.

\section{Coto VEDADO Y ÁMBiTO DE NEGOGiAGión: ¿FLEXIBILIDAD O RIGIDEZ?}

Generalmente, la mayor o menor participación ciudadana es una muestra de la mayor o menor consolidación democrática de un Estado, ya que indica el grado en el que se cumplen los principios democráticos de libertad, igualdad, mayoría, etcétera; y también evidencia la relación existente con la representatividad gubernamental de la ciudadanía. El coto vedado son los límites que hay para el ejercicio de los gobernantes y de los ciudadanos dentro de ese sistema estatal de representación democrática; en palabras de Garzón Valdés: "puede ser definido, en términos generales, como aquel ámbito constitucional que incluye principios y valores cuyo respeto y/o implementación permite asegurar un funcionamiento cabal de la democracia representativa" (Garzón 2003, 57); para que los derechos fundamentales - y otros aspectos de similar valía - no puedan ser trastocados, se impide su negociación bajo el resguardo del coto vedado. El autor sigue diciendo: "el concepto de «coto vedado» en el que han de resguardarse los derechos fundamentales no negociables, como condición necesaria de la democracia representativa. Sólo fuera de este «coto vedado» cabe el disenso, la nego- 
ciación y la tolerancia” (Garzón 2000), es decir, quien pretenda abrir la puerta del coto vedado (es decir, flexibilizarlo), para transformar derechos fundamentales en objeto de disenso y negociación, elimina la posibilidad de que la democracia satisfaga la pauta de corrección moral que de ella se espera. Más adelante califica a este coto vedado como "núcleo inviolable", con lo que el autor deja clara su rigidez.

Cohesionado al concepto de coto vedado está el de "ámbito de negociación", que hace referencia a la exclusión de algunos temas básicos de la negociación parlamentaria o de la votación ciudadana: “deben ser excluidos de la negociación y el compromiso parlamentarios todos aquellos bienes que son considerados como básicos para la realización de todo plan de vida" (Garzón 2000, 21-22); con esto, se puede considerar la existencia de "zonas" en el diseño y estructura del coto vedado, algunas de ellas prohibidas para la actuación y toma de decisiones de ciertos agentes del Estado (gobernantes y ciudadanos) y otras permitidas; ello, dependiendo de los bienes (básicos o no) que constituyan el contenido de dicha actuación y toma de decisiones. En cuanto a la vigencia efectiva de los derechos en el coto vedado de esos bienes básicos, dice Garzón, la voluntad o los deseos de la comunidad son indiferentes; es decir, no importan, al grado en el que el autor justifica la actitud paternalista — se entiende del gobiernoen caso de que dicha comunidad no comprenda la importancia de esos bienes básicos, por lo que se estaría ante la irracionalidad e ignorancia respecto a la relación causal que hay entre tales bienes y la realización de cualquier plan de vida; quien incurre en esto, dice Garzón, es incompetente básico. Hasta aquí el autor deja claramente establecida la rigidez del coto vedado y (sobre todo) del ámbito de negociación, ya que alude a la inflexibilidad en el diseño y estructura de esas "zonas" que lo constituyen, bajo la pena de menoscabar la pauta de corrección moral que se espera de la democracia; aunado a lo anterior, se debe considerar que no se podría hablar de prohibición en un determinado aspecto conductual o decisional en la vida pública estatal si tal restricción se pudiera ver "modificada" por agentes externos o razones adicionales a la esencia de tal prohibición. Sin embargo, más adelante acepta la existencia de elementos que pudieran flexibilizarlo, al decir:

Si se admite, como creo que es correcto, la tendencia a la expansión de la ética, no es aventurado afirmar que el coto vedado de los bienes básicos tiene 
también una tendencia a la expansión. Ella puede estar determinada por un doble tipo de factores: 1) factores de tipo cognitivo, es decir, la intelección de que algunas conclusiones hasta ahora no percibidas, pueden ser inferidas de las premisas del sistema ético, 2) existen también factores materiales de disposición de recursos económicos, técnicos o culturales que pueden requerir correr los límites del coto vedado (Garzón 2000, 22).

Así, el autor supedita la flexibilidad del coto vedado a la flexibilidad de la ética, con el apoyo de dos factores; el primero, que puede ser inferido del propio sistema ético, y el segundo, con base en la existencia de factores materiales e incluso culturales para que esos límites característicos del coto vedado y del ámbito de negociación se flexibilicen. Esos dos factores serán determinantes al momento de analizar los límites estatales y ciudadanos, así como su excepción en la participación ciudadana para el caso de inseguridad pública, que más adelante será abordado.

Ahora bien, una democracia está sustentada por principios, entre los cuales está el de mayoría, que se justifica en términos de lo cuantitativo en la toma decisiones al interior de una sociedad o de un Estado, en cuyo caso las decisiones por unanimidad parecen una solución adecuada para obtener legitimidad y erradicar problemas de representatividad; sin embargo, la unanimidad en sociedades cuantiosas al parecer es de difícil obtención, máxime si la sociedad de que se trata cuenta con una tradición pluralista en cuanto a la ideología; por ello, es preferible (más bien factible) que la unanimidad sea en cuanto a la posibilidad de participación en la discusión que precede a la toma de la decisión respectiva:

... si todos aquellos que pueden ser afectados por una decisión han participado en la discusión y han tenido una oportunidad igual de expresar sus intereses y justificar una solución a un conflicto, ésta será muy probablemente imparcial y moralmente correcta siempre que todos la acepten libremente y sin coerción (Nino 2003, 166).

Por ello, la discusión previa a la toma de las decisiones por parte de la ciudadanía es indispensable en un medio en el que se pretende que los principios democráticos sean la razón de la actuación tanto para gobernantes como para gobernados, independientemente de lo discutible que pudiera ser la probabilidad de la imparcialidad y de la corrección moral en el contenido de la decisión tomada con base en la premisa de la liber- 
tad y no-coerción decisional. En otro modo de verlo, la cuantificación ciudadana y poblacional es uno de los parámetros de la democracia para que la toma de decisiones pueda ser "sancionada" o no, dependiendo de un factor cuantitativo: a mayor congruencia con la ideología ciudadana y favorecimiento poblacional respecto de las políticas adoptadas en determinado aspecto, mayor correspondencia con la esencia de la democracia:

... los procedimientos políticos deberían ser diseñados para que la decisión alcanzada sea la que favorece a una mayoría o pluralidad de ciudadanos, que las leyes que dicta el complejo proceso democrático y las políticas que persigue deberían ser aquellas que, finalmente, la mayoría de los ciudadanos aprobaría (Dworkin 2004, 115 y 116).

Esa justificación cuantitativa puede reforzarse con otra de tipo utilitarista, que postula el mayor beneficio posible al mayor número de personas; sin embargo, queda la duda que contrasta la cantidad con la intensidad en cuanto a la utilidad de las decisiones tomadas por mayoría:

La justificación utilitarista obvia de la regla de la mayoría descansa sobre la posibilidad de alcanzar un determinado valor social (felicidad general, bienestar, utilidad, etc[étera]) incluso cuando éste se logre como consecuencia del autointerés de los individuos. [Sin embargo] la regla de la mayoría por sí misma no satisface el principio utilitarista, ya que para maximizar las preferencias deben ser evaluadas sus intensidades, la regla de la mayoría simple puede tener resultados antiutilitaristas si los intereses de la mayoría son mucho menos intensos que aquellos de la minoría. Así, el grado de satisfacción de preferencias agregadas es menor que el que surge de cualquier otra alternativa (Nino 2003, 107).

La discusión moral (finalmente la democracia alude a ese presupuesto de corrección) es una fuente de los derechos - específicamente los más importantes o fundamentales - y no del proceso democrático, y esos derechos, una vez surgidos, marcan los límites democráticos, es decir, el coto vedado y el ámbito de negociación surgidos directamente del raciocinio moral en un ejercicio de deliberación discursiva ciudadana:

Los derechos que nosotros hemos explorado no se derivan del proceso democrático, sino que surgen de reflexiones efectuadas sobre los presupuestos de nuestra práctica de la discusión moral. Una vez que describimos estos 
derechos, su función parece ser precisamente la de limitar la operación del proceso democrático a través de la descalificación de decisiones colectivas que los ignoran (Nino 2003, 95).

Esa discusión, fuente de la corrección moral que de la democracia se espera, es origen también de la contrastación ideológica poblacional surgida de la cosmovisión personal y singular de cada miembro de la sociedad y de la diversidad y pluralidad en la toma de decisiones, sobre todo tratándose de aspectos fundamentales y es ahí donde la unanimidad se topa con un obstáculo insalvable que intenta retener o limitar el uniformismo (casi conformismo) y que limita a un número previamente determinado de valores culturales, supuestamente aceptados por esa mayoría y prejuiciosamente considerados legales, para rechazar la idea de que la homogeneidad social es la opción más adecuada:

... pensar que sólo hay un número limitado y permitido de valores culturales y morales compatibles con la legalidad, coartando el pluralismo cultural y moral, pensando que la homogeneidad es la opción social más adecuada. La noción de integrismo resulta incompatible con la modernidad y con su cultura. La cultura de la legalidad debe ser una cultura de consenso, pero no una cultura monocolor. La cultura de la legalidad debe ser abierta, plural y crítica, nunca cerrada, intolerante ni sumisa (Ruiz 2013, 285).

Ese pluralismo y criticismo son también la base (casi principio) de la democracia y de la corrección moral que de ella se espera, la cual flexibiliza los límites dados por el coto vedado y amplía (o tal vez reduce, dependiendo del sector de la sociedad que lo mire) las zonas decisionales que diseñan y estructuran el ámbito de negociación. Aunado a lo anterior, Garzón Valdés se cuestiona acerca de la forma en la que se puede determinar y justificar el contenido y límites del coto vedado, para lo cual recurre al método de la "vía negativa", y asevera: "la tolerancia, si es que no quiere convertirse en «tolerancia boba», ha de estar enmarcada por un cerco de intolerancias, así también lo razonable requeriría el cerco de lo irrazonable" (Garzón 2000, 24 y 25); sin embargo, el autor omite aclarar el significado de lo anterior: que los límites dependen de la conceptualización que se haga de lo irrazonable, pudiendo tentativamente considerar que en cuanto lo irrazonable se modifique (no necesariamente todo, basta con que sean solamente algunas de sus categorías, o incluso una 
sola de ellas) y se convierta en razonable, el coto vedado puede variar su posición limitadora ampliando o reduciendo el ámbito de lo negociable y la "zona" de actuación (tanto estatal como ciudadana), haciendo flexible lo que antes se consideraba rígido y otorgando sentido a la maleabilidad del coto vedado, cuyo contenido y justificación es: "Tal vez no habría mayor inconveniente en utilizar aquí la expresión «irrazonable por excelencia» cuáles estados de cosas podrían ser incluidos en esta categoría: aquellos que afectan básicamente la supervivencia de la especie humana" (Garzón 2000, 25-26). Por ello, en una aproximación categórica sobre lo irrazonable se puede concluir que la salvaguarda de los intereses humanos fundamentales, que son vulnerados por los efectos de la inseguridad, es el parámetro justificatorio del contenido de esa "zona" en la que pueden libremente actuar tanto el Estado y sus órganos como los ciudadanos.

\section{LÍMITES ESTATALES Y CIUDADANOS: FUNCIÓN DEL COTO VEDADO}

El coto vedado constituye, pues, de acuerdo con la teoría, un límite para la actuación de las mayorías, y también es la razón para la positivización de reglas: "El «coto vedado» es, por ello, no sólo una barrera frente a la pretensión dictatorial de la mayoría sino también fuente de exigencias de normación positiva" (Garzón 2003, 58); es decir, a los límites cuya finalidad es salvaguardar circunstancias fundamentales de la sociedad y de su funcionamiento, se le debe agregar el correlativo lógico: las reglas bajo las cuales se puede permanecer dentro de los límites y las reglas por las cuales no se deben rebasar, ya que los límites no solamente nos muestran a dónde no podemos ir, sino que también nos muestran a dónde sí podemos ir; por ello, se vuelve una exigencia del coto vedado la normación positiva, así como la justificación del ámbito de lo negociable y, más que eso, las reglas para su negociación, todo ello con la finalidad de que realmente se protejan esas circunstancias y derechos fundamentales que intenta proteger. Cuando hay cumplimiento de lo anterior, es decir, cuando hay esa normación positiva, hay entonces efectivización, y no es solamente una idea sin aplicación alguna; en caso contrario, esos dos aspectos del coto vedado (límites y positivización) en lugar de complementarse correlativamente estarían siendo contradictorios: 
cuando [el coto vedado] se convierte en una declaración puramente retórica, la sociedad tiende a la exclusión de la mayoría de sus miembros. Vistas así las cosas, ambos aspectos del "coto vedado" apuntan en direcciones que podrían ser consideradas como opuestas: la prohibición de politizar lo no negociable y la exigencia de asegurar políticamente la realización efectiva de los derechos que intenta proteger (Garzón 2003, 58).

Ahora bien, el autor no lo menciona, pero esa exigencia de normación positiva está dirigida al Estado (ente productor de la legislación), y como correlativo lógico de esa actividad legislativa se encuentra el respeto (por parte del mismo Estado) de esas leyes, lo que significa que para el Estado (órganos de representación incluidos) la exigencia es triple: 1) el respeto a los límites establecidos que salvaguardan derechos fundamentales; 2) crear legislación cuyo objetivo sea establecer las reglas de actuación dentro de esos límites y justificar su prohibición fuera de ellos, y 3) respetar esa legislación creada, lo cual incluye realizar las acciones necesarias y suficientes para generar conformidad y coherencia con la misma. Asimismo, la normación positiva representa, además de la creación de normas jurídicas, el establecimiento de las instituciones necesarias para su ejecución y observancia, y eso constituye un elemento estatal fundamental para que la actuación de la ciudadanía dentro del coto vedado sea efectiva. Con esto se hace referencia a la importancia del enfoque institucional: "La existencia de instituciones sin participación supone el riesgo de meros aparatos legales formales carentes de vida. La participación sin instituciones supone el riesgo de una simple protesta en el vacío" (Beliz 2012, 22); a la normación positiva y a la institucionalización para su ejecución se le agrega la actuación de la ciudadanía que adopta la forma de deliberación o discusión de los problemas sociales, en virtud de que el contenido del coto vedado ${ }^{6}$ debe ser "razonado" por la propia ciudadanía para su determinación. Pero, ¿cuáles son las condiciones de esa deliberación? Al respecto:

... necesita unos requisitos para que pueda funcionar si no hay libertad de información, los individuos no pueden recoger todos los datos y sus argumentos andarán mancos si los individuos tienen entre ellos relaciones de poder, como las que derivan de desigualdades económicas, la deliberación estará

\footnotetext{
6 Para el caso en el que la conceptualización de lo irrazonable cambie a razonable.
} 
pervertida. Si, cuando yo expreso un juicio contrario al tuyo, tú puedes tomar represalias contra mí, es fácil que yo evite replicarte (Ovejero 2002, 218).

De lo anterior se derivan tres condiciones para la deliberación: 1) libertad y derecho de información; 2) objetividad en las relaciones interpersonales, y 3) tolerancia ante la diferencia de ideas. Si no se reúnen estos tres elementos, entonces el ejercicio cívico de la deliberación y discusión estará viciado, y el producto no será democrático, sino que generará una tensión - incluso rompimiento - entre los límites de la actuación de los órganos estatales y los de la ciudadanía, que significaría la expansión innecesaria e ilegítima de las "zonas" de actuación, tanto de la prohibida como de la permitida, flexibilizando irrazonablemente el coto vedado y el ámbito de negociación. La manera de evitar lo anterior es "razonabilizando" lo irrazonable, lo cual sucede precisamente utilizando la deliberación y discusión ciudadana. Con esto se pretende que las mayorías y las minorías equilibren su participación estatal, y que los límites razonables del coto vedado sigan teniendo la vigencia protectora de lo fundamental, evitando así el abuso del poder y el exceso en la toma de decisiones de las minorías que desemboca en el totalitarismo:

In an industrial, scientific and nuclear age, life in a democracy, just as in a totalitarian society, is shaped by a handful of people. Major political, economic and social decisions are made by tiny minorities, not the masses of people... democracy is government "by the people", but the survival of democracy rests on the shoulders of elites. This is the irony of democracy: elites must govern wisely if government "by the people" is to survive. The masses do not lead, they follow. They respond to the atittudes, proposals, and behavior of elites (Dye y Zeigler 1997, 155).

Sin embargo, la participación de las mayorías es indispensable en una democracia, y es imprescindible tratándose de la conformación y diseño del coto vedado, que no solamente debe quedar al arbitrio de los órganos estatales, sino que también puede ser discutido y deliberado por la población buscando su posible transformación razonable:

la participación de masas es un elemento indispensable para toda comunidad democrática. En su ausencia, los líderes se tornan irresponsables ante las necesidades de las personas. $\mathrm{Al}$ extenderse la brecha entre gobernantes y go- 
bernados, las masas pueden tornarse alienadas, desentendidas y mezquinas y, al suceder esto, se expone a la democracia a las arremetidas de movimientos de masas antidemocráticos. Lo que es más importante, una "democracia" que elimine la participación de masas llegando al grado de promover su no participación, niega a los estratos más grandes de la población los beneficios derivados de la participación política, socavando así su principal razón de ser, vale decir la promoción del bienestar general (Bachrach y Botwinick 1994, 136 y 137).

Todo lo anterior da pauta para cuestionar acerca de las posibles excepciones a los límites de la participación ciudadana para el caso del fenómeno de la inseguridad pública.

\section{EXCEPCIÓN A LOS LÍMITES DE LA PARTICIPACIÓN CIUDADANA PARA EL CASO DE LA INSEGURIDAD PÚBLICA}

La flexibilidad tanto del coto vedado como del ámbito de negociación tienen como parámetro, como ya quedó establecido, el sistema ético y ciertos factores materiales y culturales, que son determinantes para los límites estatales y ciudadanos, así como para la excepción a los límites de la participación ciudadana en caso de inseguridad pública; por ello, lo razonable (y su contraparte irrazonable) constituyen una aproximación categórica, que conduce a la salvaguarda de los intereses humanos fundamentales y constituyen también la justificación de la "zona" en la que libremente pueden actuar tanto el ente estatal como la ciudadanía; producto de esto es la reflexión sobre los límites estatales y ciudadanos como una de las funciones del coto vedado. Asimismo, la exigencia de normación positiva con carga al Estado y su correlativo lógico determinado en el respeto a la misma es una exigencia tripartita, que incluye el respeto a los límites que salvaguardan derechos fundamentales, la creación de legislación para establecer las reglas de actuación dentro de esos límites - para justificar su prohibición fuera de ellos - y el respeto a esa legislación creada. Ahora bien, en una democracia la participación del ciudadano es indispensable, ya que deriva de la esencia democrática referida al concepto más básico de un gobierno conformado por el pueblo, ya que dicha conformación se realiza necesariamente cuando el ciudadano toma parte en los asuntos públicos para decidir 
quién será el que detente un cargo público y el que lo represente; por ello, también la participación ciudadana es un derecho:

la participación ciudadana es una forma de entender el ejercicio del poder donde los sujetos, entendiendo por tal a los ciudadanos, forman parte activa de la gestión pública; la participación ciudadana es un derecho ciudadano fundamental, configurándose como un prerrequisito para el ejercicio de otros derechos (Mujica 2008, 22).

Asimismo, derivados también de la esencialidad democrática que informa el contenido de la propia participación ciudadana están los límites a la misma; es decir, el contenido relativo a los derechos fundamentales que protege el coto vedado también justifica los límites de actuación de la ciudadanía (y no solamente, como ya se ha dicho, los del Estado) y de sus diversas vertientes, como las minorías. Los límites basados en el sistema ético sufren variación cuando la concepción fundante de dicho sistema muta, al grado de variar las concepciones de lo razonable, que se aproximan a las de lo irrazonable: "aquellas máximas o reglas de conducta que propician la imposición de un mal son prima facie irrazonables" (Garzón 2005, 33), lo que constituye una premisa básica en la determinación de lo irrazonable, como lo es la violencia y sus consecuencias en cuanto a inseguridad pública: las reglas jurídicas del Estado que se supone deben regir la seguridad ciudadana no han logrado su cometido y trae como consecuencia la imposición de ese mal, por lo que tal sistema estatal se vuelve irrazonable. Ahora bien:

si la aplicación concreta de una regla tiene consecuencias absolutamente irrazonables, esa regla debe ser abandonada: es absolutamente injustificable si la aplicación concreta de una regla tiene consecuencias "prima facie" irrazonables, esa regla debe ser sometida a examen y modificada o especificada de forma tal que aquéllas desaparezcan (Garzón 2005, 33).

Aquí se encuentra la justificación para el abandono de una regla cuyas consecuencias son absolutamente injustificables, como la inseguridad, que es una circunstancia derivada de la deficiente ejecución estatal de las reglas de conducta dirigidas a solucionar dicho problema. Sigue diciendo el autor que "acuerdos razonables no son aquellos que realizan personas razonables sino que personas razonables son aquellas que no se saltan 
el cerco de la irrazonabilidad" (Garzón 2005, 33); por tanto, actuación estatal razonable es aquella que no rebasa lo establecido en la ley como irrazonable, que no infringe la norma jurídica en dos sentidos: el primero, no llevando a cabo conductas que excedan lo establecido jurídicamente, y segundo, llevando a cabo aquellas que están contenidas jurídicamente en forma de atribuciones. De nueva cuenta, si consideramos (con base en la evidencia y los elementos fácticos ya expuestos) que el Estado ha fallado en cuanto a la realización de las acciones necesarias para garantizar la seguridad pública (que es además una de sus finalidades), entonces es una circunstancia irrazonable que debe ser sometida a examen y, eventualmente, ser modificada. Lo anterior constituye una excepción a los límites de la participación ciudadana para el caso de la inseguridad pública.

Por ello, una sociedad segura es aquella que cuenta con un equilibrio razonable (o "razonabilizado") entre los límites ciudadanos y los límites estatales, derivado del respeto al coto vedado y al ámbito de negociación y de la adecuada deliberación, y cuya tensión entre los límites estatales y los ciudadanos está controlada y mesurada de acuerdo con el respeto a las circunstancias fundamentales del ser humano determinadas por su discusión y deliberación. Lo anterior implica ciertos aspectos relacionados con las actitudes morales y jurídicas que deben ser alentadas en y para una sociedad segura en la estructura estatal encargada de la seguridad (como los cuerpos de policía y ejército), aspectos como la educación y la actitud derivadas de la democracia pueden (tal vez deben) permear también en los aspectos de seguridad ciudadana. ${ }^{7}$ En ese mismo sentido, el accountability social es una forma de control que toma en cuenta procedimientos

7 Incluso se ha considerado que una fuerza militar no administrada de forma democrática, es decir, no involucrada a la trama social, puede ser una amenaza para la democracia a través de prácticas no autorizadas, uso indebido o consumo excesivo de fondos públicos o la violación de derechos humanos; asimismo, ha habido propuestas en la implementación de mecanismos para generar disposición democrática entre el personal del sector de la seguridad, que se basan en la lealtad a la Constitución y a las instituciones estatales, un orden interno del sector de seguridad bien definido, la educación en valores y normas fundamentales, la neutralidad política, la legalización de la desobediencia a las órdenes ilegales o abusivas y presencia de civiles en la plana mayor del sector de la seguridad; este último elemento en razón de que el funcionario encargado de la seguridad debe ser asesorado no solamente por generales, sino también por civiles, para asegurar un proceso de decisiones equilibrado (véase Centro de Ginebra para el control democrático de las fuerzas armadas, Unión interparlamentaria, s. d., 149). 
cuasijudiciales en ámbitos de negociación y decisión no judiciales, y el accountability institucional se ejerce por agencias estatales, aunque su ejercicio está liderado por ciudadanos: "dicho control se lleva a cabo por los ciudadanos, las organizaciones y los movimientos sociales, pero ya no a través de instancias electorales, sino mediante denuncias, manifestaciones, protestas y diversas formas para expresar su malestar y repudio frente a determinados acontecimientos" (Ruiz 2013, 248); en cuanto a la clasificación de la participación ciudadana, algunos autores (Mujica 2008, 24-35) incluyen lo que llaman "mecanismos modernos de participación" (más allá de los clásicos instrumentos representativos) desde las instituciones o instancias, como: a) la participación en la definición, ejecución y evaluación de la gestión pública; b) la participación en programas presupuestales; c) mecanismos de debate, y d) encuestas deliberativas; pero también mencionan el control ciudadano basado en: a) disposición de recursos sancionadores para el ejercicio del control; b) el derecho a la información y los espacios de discusión, y c) habilitación del los sujetos de control ciudadano; finalmente, desde un grado de incidencia de la participación, ésta puede ser: a) consultiva, b) decisoria (la ciudadanía da una opinión vinculante), y c) como cogestión. ${ }^{8}$ Todo lo anterior da cuenta de la importancia que ha ido cobrando - tanto desde el punto de vista doctrinal como en la realidad social - la supervisión enfocada de parte de la ciudadanía hacia los órganos del Estado encargados de la seguridad pública. Por ello, "el diálogo es el mecanismo a través del cual la democracia convierte las preferencias autointeresadas en preferencias imparciales" (Nino 2003, 202), y entre las ventajas que tiene la participación ciudadana hay autores que mencionan: a) involucra a los ciudadanos en los asuntos públi$\cos$; b) permite redistribuir riqueza, mediante el señalamiento de las prioridades sociales en el gasto; c) vuelve a unir a gobernados con gobernantes, y d) combate a la corrupción a través de mecanismos de control ciudadano (Cortina 1993, 25-40). En este punto no se puede omitir el principio normativo de publicidad como mandato de accesibilidad, el cual "se refiere no sólo a la publicación de las medidas legales, administrativas y judiciales, sino al acceso al procedimiento que precedió a la promulgación o

8 Como grado de influencia máxima de la sociedad civil con intervención en los procesos de diseño de política pública, en su etapa de ejecución e, incluso, en la de evaluación (Mujica 2008, 33 у 34). 
dictado de estas medidas" (Garzón 1993, 81-82). Lo anterior se interpreta como la importancia de que el ciudadano controle al gobernante; pero no en todos los Estados democráticos contemporáneos se cuenta con los mecanismos - tanto legales como institucionales - para hacerlo efectivo, mismo que se traduce en la no plenitud ni efectividad del derecho por sus propósitos no logrados, lo cual puede provocar ciertas soluciones jurídicas (y sociales) excepcionales, como la resistencia: "la crisis de efectividad del derecho puede desencadenar soluciones jurídicas excepcionales como el derecho a la resistencia, entendido [como el] rechazo a las actuaciones del poder público que afectan, disminuyen o anulan sin razón los derechos de los administrados" (Hernández 2015, 44); asimismo, hay quien considera que la seguridad ciudadana "no es tarea exclusiva de los policías, sino que incluye a todos los ciudadanos trabajando y demandando una mayor eficiencia en el aparato judicial, una mejor presentación de servicios públicos" (Instituto de Defensa Legal. Centro de Promoción Social para la Seguridad Ciudadana, 2003,163). Una perspectiva de responsabilidades compartidas entre el gobierno y la ciudadanía parece la respuesta más adecuada para la solución del problema de la inseguridad, sobre todo cuando el aparato estatal no ha cumplido esas finalidades; por ello, la seguridad ciudadana debe ser una función también de la ciudadanía y no solamente de las instituciones gubernamentales o del órgano estatal policiaco; la seguridad pública tiene las limitaciones inherentes a las fallas del Estado, mientras que la seguridad ciudadana puede potencializar esas funciones estatales con una mayor presencia y con una responsabilidad compartida entre el gobierno y los ciudadanos.

En otro concepto de seguridad ciudadana se puede hacer referencia a la seguridad comunitaria, en la cual se tiene en cuenta al ciudadano en la formulación y verificación de las políticas de seguridad (Brotat 2002, 4). En una consideración cuantitativa, la ciudadanía podría superar la limitante numérica que obstaculiza el actuar - o la eficacia - de la policía y el órgano gubernamental del que depende, y ser una posible solución a la inseguridad. En la participación ciudadana para la seguridad se proyecta (exceptuando sus límites) un actuar más protagonista e importante para el ciudadano: ya no es solamente el ente pasivo que recibe o en el que recae el efecto del actuar estatal, sino que ahora es parte integrante del Estado. Ciertas recomendaciones para las policías comunitarias comprenden la descentralización, el ejercicio de la información y la consecuente eva- 
luación, la participación comunitaria basada en estructuras participativas inclusivas, la rendición de cuentas, área de asuntos internos y auditorías (Ungar 2012, 36). ${ }^{9}$

\section{MéXico y COLOMBIA: CASOS DE EXCEPCión AL COTO VEDADO}

En América Latina y el Caribe existe un gran problema de inseguridad ciudadana, ${ }^{10}$ específicamente en Colombia (aunque el fenómeno ya ha disminuido de forma importante en este país) y en México, donde en los últimos años se ha sufrido el fenómeno de la violencia y la delincuencia, que ha afectando directamente a la seguridad pública, de ahí el sentir de la ciudadanía mexicana, incluso llegando al punto en el que le da más importancia a que las autoridades capturen a personas acusadas de cometer algún delito sobre el hecho de que las autoridades respeten los derechos humanos; ${ }^{11}$ por ello, no es infrecuente que haya autores que lo consideran un panorama desolador:

En México se vive un panorama desolador: empoderamiento del Estado por el poder transnacional, pérdida de soberanía, violencia y alza de la oferta de criminalidad, miseria e inequidad crecientes, ausencia de mercados transparentes y eficientes e informalidad creciente de la economía (Massé 2007, 38).

Tales fenómenos ya han provocado que la ciudadanía organizada realice actos que van más allá de lo permitido, haciendo realidad la excepción al coto vedado, y van yendo más allá de lo que (como ciudadanos) pueden hacer: "la contracara de procesos de participación sin institucionalidad

\footnotetext{
9 Ungar (2012), citado por: Beliz (2012,36) Gustavo.
}

10 Con tasas que alcanzan 24.5 homicidios por cada 100,000 habitantes, es decir, tres veces superior al promedio mundial de ocho homicidios por cada 100,000 habitantes; siendo Centroamérica la subregión con mayor problema, al tener una tasa de 33.6 homicidios cada 100,000 habitantes, y en el Cono Sur, con 10.9 homicidios por cada 100,000 habitantes; véase, Beliz (2012).

$11 \mathrm{Al}$ respecto, véase la gráfica 1.3 en la que se muestra la cantidad de respuestas que se dan al reactivo "En su opinión qué es más importante, ¿que las autoridades respeten los derechos humanos o que las autoridades capturen a personas acusadas de cometer algún delito?", Instituto Nacional Electoral. 2015. "Informe país sobre la calidad de la ciudadanía en México", disponible en: http://www.ine.mx/archivos2/s/DECEYEC/EducacionCivica/ Resumen_Ejecutivo_23nov.pdf(consultado el 21 de febrero de 2017).

Esta obra está bajo una Licencia Creative Commons

Atribución-NoComercial-SinDerivar 4.0 Internacional, IIJ-UNAM.

Boletín Mexicano de Derecho Comparado, núm. 157, enero-abril de 2020, pp. 243-270. 
estatal sólida se presenta a través de los aspectos negativos de la privatización de la violencia y la justicia por mano propia, y los fenómenos de ajusticiamiento que también resultan extendidos en ciertas áreas de la región" (Beliz 2012, 22). Un factor importante de la anterior cita es la ausencia (o escasez) de una institucionalidad estatal sólida, lo que implica una falla en las funciones del Estado de la cual se deduce la irrazonabilidad de su funcionamiento y se desprende la justificación para que el coto vedado sea maleable. Lo anterior es así, ya que "Un grado óptimo de gobernabilidad democrática implicaría una reducción considerable de conflictos violentos, pues si el instrumental del Estado funciona correctamente, se asegura la intermediación institucional" (Alarcón 2009, 36). En México, derivado de los acontecimientos que vulneran la seguridad social y ciudadana, surge la duda sobre si la democracia ha funcionado o no. Una creciente desconfianza invade el ánimo ciudadano, ya sea entre los propios ciudadanos o entre éstos y las autoridades e instituciones que intentan materializar al Estado y sus funciones. ${ }^{12}$ La esencia del Estado se ve vulnerada por la idea de que la ciudadanía sea la corresponsable de la seguridad; sin embargo, la seguridad es un bien común que debe ser tutelado y garantizado por el Estado. ${ }^{13}$ El contraste de lo anterior surge de la opinión pública mexicana:

12 Los resultados presentados por el Instituto Nacional Electoral (2015) demuestran este aspecto, sobre todo tratándose de dimensiones como cultura de la legalidad (en la que se incluyeron aspectos como la preferencia de la ciudadanía de capturar presuntos delincuentes sobre el respeto de los derechos humanos por parte de las autoridades o el respeto concreto de las leyes, las denuncias de los delitos y la eficacia de las autoridades frente a las que se denunció).

13 Idea desarrollada desde los teóricos clásicos del Estado, pero de forma paradigmática Thomas Hobbes la plantea en su teoría contractualista, donde dice que el hombre debe asegurar su permanencia y conservación en este mundo a través del cumplimiento de la ley de la naturaleza, que ordena a los hombres buscar la paz, lo cual, para lograrlo, es necesario defenderse de quienes se le oponen; de ahí la necesidad de un contrato para garantizar la armonía, en el que cada uno prescinde de ciertos derechos cuando los demás están dispuestos a hacer lo mismo; para que ese pacto se respete, dice, se requiere de la justicia y de una autoridad política con poder suficiente para asegurar esa cooperación pacífica: la renuncia de los derechos que se poseían en estado de naturaleza mediante el acto contractual implica otorgarlos a un soberano que garantice el orden y la seguridad: "For the Lawes of Nature (as Justice, Equity, Modesty, Mercy, and (in summe) Doing To Others, As Wee Would Be Done To, ) if themselves, without the terrour of some Power, to cause them to be observed, are contrary to our naturall Passions, that carry us to Partiality, Pride, Revenge, and the like. And Covenants, without the Sword, are but Words, and of no strength to secure a man at all. Therefore notwithstanding the Lawes of Nature, (which 
en quien más desconfía la ciudadanía es en los políticos que gobiernan el país, seguido de la policía. ${ }^{14}$ Lo anterior, aunado a que la corrupción sigue siendo una de las principales razones por las que la gente desconfía de la policía con un $54 \%$ de opiniones al respecto, la percepción que se tiene de abuso policial con 28\%, y el hecho de haber tenido malas experiencias personales o de alguien cercano con un 19\%, además de que un $13 \%$ considera que la policía está de alguna manera vinculada con grupos delincuenciales, $11 \%$ sienten que no hacen su trabajo, y otro porcentaje similar de que no están debidamente capacitados; por tanto, no se puede confiar en ellos. ${ }^{15}$ Como corolario a lo anterior, y con relación a las políticas públicas que se han adoptado en México ante el problema creciente de la inseguridad, no se puede obviar el tema de las reformas legales ${ }^{16}$ que han apostado, como siempre, a que una modificación de forma al sistema jurídico tendrá implicaciones positivas en la realidad social (lo que no siempre es acertado), dichas reformas han modificado los límites (coto) de la actuación institucional para abatir el fenómeno. Sin embargo, a pesar de todas esas políticas públicas implementadas y del esfuerzo institucional y estatal que se ha hecho para mejorar el problema de la inseguridad, tal objetivo no se ha logrado como se esperaba

Por otro lado, en Colombia ha habido diversos esfuerzos en cuanto a políticas públicas para abatir el fenómeno de la inseguridad pública, los cuales han tenido éxito a la luz de lo acontecido en los últimos años; por

everyone hath then kept, when he has the will to keep them, when he can do it safely,) if there be no Power erected, or not great enough for our security; every man will and may lawfully rely on his own strength and art, for caution against all other men" (Hobbes 1651, 302).

14 De acuerdo con datos obtenidos de la presentación "Ser policía en México: ¿Qué rol asume la sociedad? Reporte ejecutivo de resultados", Centro de Opinión Pública UVM e Instituto para la Seguridad y la Democracia A. C., (2017).

15 Idem.

16 Como la Policía Federal Preventiva (PFP) por nueva ley publicada en el Diario Oficial de la Federación el 4 de enero de 1999; la Secretaría de Seguridad Pública (SSP), creada por decreto que reformó la Ley Orgánica de la Administración Pública Federal el 30 de noviembre de 2000; la Agencia Federal de Investigaciones (AFI), por decreto que reforma la Ley Orgánica de la Procuraduría General de la República el 1o. de noviembre de 2001; los juicios orales y el sistema acusatorio en materia penal, por reforma a la Constitución Política de los Estados Unidos Mexicanos el 18 de junio de 2008; el Sistema Nacional de Seguridad Pública (SNSP) por nueva ley publicada en el Diario Oficial de la Federación el 2 de enero de 2009; y la propuesta de unificar la policía federal. 
tal motivo, es un caso de interés en cuanto a la flexibilización del coto vedado en la participación de la ciudadanía. Algunos autores han manifestado su beneplácito respecto a las reformas que modificaron la Constitución Política de Colombia con la finalidad de enfrentar el terrorismo, así como una ley estatutaria que deberá reglamentar las facultades que esa reforma confiere a ciertas autoridades para interceptar correspondencia y realizar detenciones, allanamientos y registros domiciliarios (Younes 2004). Esto parece ser una flexibilización en materia de coto vedado, al menos desde el punto de vista formal, ya que los límites impuestos a los gobernantes se amplían invadiendo un poco los aspectos prohibidos (por fundamentales), pero con la debida justificación del caso. Asimismo, un autor colombiano (Younes 2004) manifiesta que la nueva Constitución define la paz como un derecho y como un deber de obligatorio cumplimiento, y hace referencia a los factores que causan la violencia; dice que es "la duda en la ley y la imposición de la justicia por la propia mano"; agrega que la Ley 418 de 1997 dictó disposiciones para facilitar el diálogo y acuerdos para la paz y como una obligación del Estado de propender por un orden social justo que asegure la convivencia pacífica. Lo anterior es una muestra de la importancia que se le ha dado en ese país a la constitucionalización y regulación legal (que no deja de flexibilizar los límites analizados en este trabajo) para el caso de la seguridad. Otro autor dice:

Bajo el principio de "progresividad" la CG [Corte Constitucional] de Colombia ha podido frenar medidas económicamente lesivas a derechos esenciales (como la disminución de seguridad social) y revisar políticas públicas como parte del control constitucional ello ha sido posible debido a la fuerza normativa de la Constitución, lo que permite a la corte ampliar su radio decisorio y dar la solución que mejor se adapte a la regularidad constitucional (De Paz 2016, 237).

En Colombia están regulados constitucionalmente tres estados de excepción: a) el estado de guerra exterior, b) el estado de conmoción interior, y c) emergencia; respecto al estado de conmoción, dicha Constitución establece:

En caso de grave perturbación del orden público que atente de manera inminente contra la estabilidad institucional, la seguridad del Estado, o la convivencia ciudadana, y que no pueda ser conjurada mediante el uso de las 
atribuciones ordinarias de las autoridades de policía, el presidente de la República, con la firma de todos los ministros, podrá declarar el estado de conmoción interior, en toda la República o parte de ella (Constitución Política de Colombia. Actualizada con los actos legislativos a 2015, 2017).

\section{Algunos autores afirman que}

el restablecimiento del orden alterado por los hechos perturbadores, no sería posible si no se reconoce en cabeza del presidente un adecuado margen de discreción. Declarado un estado de excepción, los decretos que como consecuencia dicta el presidente, se originan en una competencia discrecional (Cifuentes 2002).

Asimismo, hay quien afirma que en la figura de los estados de excepción suelen entrar en conflicto las "razones de Estado" frente a la vigencia del Estado de derecho, ya que en ocasiones la defensa estatal justifica la adopción de cualquier medio para protegerlo de las amenazas que atacan su estabilidad y, a la vez, constituye la legitimación de la ruptura de la legalidad (Ariza 1997); dicha legitimación constituye la justificación para la flexibilización de los límites con base en la irrazonabilidad de las consecuencias del fenómeno de inseguridad. Además, la participación ciudadana como una fuente de la democracia implica también que se involucre de manera más intensa en los asuntos estatales, bajo la justificación mencionada, lo que en ese país se aprovechó de forma cabal:

El cambio en la estructura mental de los individuos de una sociedad debe estar dada por elementos de juicio que le permitan deliberar sobre qué decisiones deben tomar en cuanto al rumbo que dicha sociedad quiere, es por ello que se hace necesario que cada uno de los miembros de ese cuerpo social tenga la capacidad de deliberar y de esa manera "constituir" a través de un verdadero contrato social el modelo de sociedad que quieren. El modelo que se quiere estudiar aquí es una forma de organización social que nació como una salida alternativa al conflicto armado en Colombia y que trascendió a la esfera de la administración pública, articulando un trabajo mancomunado entre ciudadanía y administración pública; es un fenómeno muy interesante que demuestra la importancia que el ciudadano común y corriente se empodere y que su ejercicio como tal trascienda del simple hecho de depositar un voto en una urna, a un espacio de discusión donde su voz y voto sea determinante en la aplicación de las políticas públicas (Cadrazco 2009,17). 
Ese cambio en la estructura mental de la que habla el autor solamente podría darse con la permisión en la modificación de los límites establecidos para las zonas de negociación, ya que sin ese requisito el ciudadano podrá tener las mejores intenciones de participar y de involucrarse en los asuntos de su sociedad, pero si las reglas jurídicas no lo permiten no lo va a poder hacer, llegando al extremo de tener que legitimar la flexibilización de tales límites bajo la justificación de salvaguardar derechos fundamentales que el Estado no ha podido:

Desde la década anterior, por la situación de desencanto tanto con el Estado como con las propuestas del movimiento armado, la sociedad civil ha venido dando cuenta de su capacidad de acción y reacción en la búsqueda de pedir o solucionar las necesidades básicas de tipo material y además en la búsqueda de espacios de participación, construyendo modelos de un nuevo qué hacer político. Los movimientos cívicos, los paros y marchas, los movimientos de pobladores citadinos, las nuevas dimensiones del movimiento indígena y, en general, de las minorías étnicas, los grupos religiosos, ecológicos, las organizaciones juveniles, son una muestra de la vigorización de la sociedad civil y de su polifacética expresividad (Cadrazco 2009, 24).

En contraste con la participación ciudadana en tales circunstancias sociales, si bien la injerencia de los ciudadanos colombianos en los procesos constitucionales ha sido poca, el impacto ha sido sustancial:

podemos destacar de ese ejercicio tres acontecimientos que a nuestro parecer son los más importantes. El primero de ellos es [el] plebiscito del año de 1957. El segundo de ellos establece la votación popular de alcaldes y gobernadores, el 21 de noviembre de 1984, con el fin de reducir o eliminar el control central de los partidos sobre sus nominaciones y ampliar la democracia regional, comienza con esto la descentralización administrativa y la posibilidad de elegir a los mandatarios locales y por último el ya mencionado movimiento que dio origen a la Carta de 1991 (Cadrazco 2009, 24).

Finalmente, derivado de las experiencias colombianas, hay quien afirma que el derecho no constituye una vía de paz, sino de guerra:

... el derecho no es la paz sino la guerra, la guerra ritual. Y el dominio del derecho es el dominio de un saber polémico, una retórica estratégica, una gramática de y para la guerra civil que es la vida cotidiana en la historia 
constitucional colombiana, una hipótesis tal puede ser verificada de manera paradigmática en la medida en que el proceso de construcción nacional ha sido reducido y absorbido por la tradición constituyente [la cual] no ha sido más que una batalla interminable entre élites y partidos, cartas y enmiendas el culto del orden, el apelar sin tregua y sin pausa al círculo vicioso del reformismo constitucional y bloquear así el acceso del pueblo y de terceras fuerzas del Estado, ha transformado a Colombia en una sociedad violenta, que recurre una y otra vez a la guerra política (Valencia 2014, 197-198).

El autor continúa diciendo que las armas han proliferado y las leyes han sido empleadas como armas, y que la herencia de los colombianos es la violencia, por lo que insta a luchar por la imaginación política en lugar del reformismo constitucional, por la democratización y el cambio, en lugar de la continuidad y el orden a cualquier precio (Valencia 2014, 197 y 198), manifestaciones que representan el sentir en ese país respecto a las afectaciones que han provocado los sucesos de violencia y criminalidad que históricamente se han registrado, pero que dejan una invaluable experiencia aprovechable en México y en Latinoamérica - y tal vez en el mundo - respecto a que los límites constitucionales y legales establecidos y ejecutados por las instituciones estatales no siempre se deben cumplir, atendiendo a la irrazonabilidad que provocaría - y que ha provocadosu cumplimiento y que, en última instancia, significa la posibilidad de flexibilizar los límites para salvaguardar lo que el Estado no ha podido de forma adecuada: la seguridad pública.

\section{CONCLUSIÓN}

El coto vedado y el ámbito de negociación no son rígidos: su contenido conceptual depende del sistema ético y de su flexibilidad, pues los límites éticos cambian cuando su concepción fundante cambia en razón de la presencia de inseguridad pública; por tal razón, la excepción a los límites surge cuando esas funciones exclusivamente estatales dejan de ser cumplidas y el sistema se vuelve irrazonable, justificando la maleabilidad del coto vedado. El principio de mayoría asegura una mayor cantidad de corrección moral con base en un mayor número de sujetos que postulan discusiones morales y marca los límites democráticos; además, el pluralismo que deriva de lo anterior flexibiliza los límites dados por el coto vedado, ampliando o 
reduciendo el ámbito de negociación, de modo que para evitar que haya tensión y rompimiento entre los límites de actuación estatales y ciudadanos se debe ejercitar la deliberación y discusión ciudadana. A contrario sensu, una sociedad segura es aquella que cuenta con un equilibrio razonable (o "razonabilizado") entre los límites ciudadanos y los límites estatales derivado del respeto al coto vedado y al ámbito de negociación y de la adecuada deliberación, cuya tensión entre los límites estatales y los límites ciudadanos está controlada y mesurada de acuerdo con los propios límites fundamentales del ser humano y determinados por su propia razón.

Una falta de institucionalidad sólida implica una falla en las funciones del Estado, de lo cual surge la irrazonabilidad de su funcionamiento y se desprende la justificación para que el coto vedado sea maleable. El caso colombiano es una muestra de que el coto vedado puede ser flexibilizado en la realidad social, lo que se robustece por la posibilidad legítima de hacerlo en otros Estados, en función de la razonabilidad de su justificación derivada de las circunstancias especiales que afectan el sentido de supervivencia humano en caso de seguir aplicándose. Por tanto, los límites jurídicos establecidos y ejecutados por las instituciones estatales para la participación del ciudadano no siempre se deben cumplir, atendiendo a la irrazonabilidad que provocaría su cumplimiento, y esto significa flexibilizar los límites para salvaguardar la seguridad pública.

\section{BIBLIOGRAFÍA}

Alarcón, César. 2009. "Crimen organizado y gobernabilidad democrática en México. Entre la prevención de conflictos y la seguridad nacional. Alternativas para el futuro", Seguridad humana, posibles soluciones a un conflicto, México, UNAM.

ARIZA, Libardo et al. 1997. Estados de excepción y razón de Estado en Colombia, Bogotá, Universidad de los Andes, Estudios Ocasionales CIJUS.

BACHRACH, Peter y BoTwINICK, Aryeh. 1994. "Análisis y reconstrucción teórica de la teoría participativa”, en Pichardo PAGAZA, Ignacio (comp.), Política social y participación, México, Editorial Mac.

BELIZ, Gustavo. 2012. "Gobernar la seguridad ciudadana en América Latina y el Caribe. Amenazas, desafios y nudos estratégicos de gestión”, Banco Interamericano de Desarrollo (BID), Sector de Instituciones para el Desarrollo, documento de debate \# IDB-DP-215, Washington D. C., BID. 
BROTAT JUBERT, Ricard. 2002. "Un concepto de seguridad ciudadana", disponible en: http://gfw.diputacionalicante.es/repo/rec/87/BROTAT_seguridad_ciudadana.pdf

Cadrazco Salcedo, Orlando José. 2009. "La participación ciudadana como fuente de democracia", Revista Pensamiento Americano, 2(2).

Centro de Ginebra para el Control Democrático de las FuerZAS ARMADAS, UNIÓN INTERPARLAMENTARIA. s. d. "Guía práctica de parlamentarios núm. 5-2003. Control parlamentario del sector de la seguridad: principios, mecanismos y prácticas", disponible en: http:// wrere.oas.org/dsp/parlamentarios/guate/control_parlamentario_sector_segurida. $p d f$.

Centro de Opinión Pública UVM e Instituto para la Seguridad Y La Democracia A. C., INSYDE. 2017. "Ser policía en México: ¿qué rol asume la sociedad? Reporte ejecutivo de resultados", disponible en: http://insyde.org.mx/wp-content/uploads/16-02-2017-Reporte-ejecutivo-estudio-Ser-polic\%C3\%ADa-en-México-CopUVM-Insyde.pdf.

Cifuentes MuÑoz, Eduardo. 2002. "Los Estados de excepción constitucional en Colombia", Ius et Praxis 8(1).

DiARIO OFICIAL DE LA FEDERACIÓN. Órgano del Gobierno Constitucional de los Estados Unidos Mexicanos. 1999, t. DXLIV, núm. 1.

DiARIO OFICIAL DE LA FEDERACIÓN. Órgano del Gobierno Constitucional de los Estados Unidos Mexicanos. 2000, t. DLXVI, núm. 22.

DiARIO OFICIAL DE LA FEDERACIÓN. Órgano del Gobierno Constitucional de los Estados Unidos Mexicanos. 2001, t. DLXXVIII, núm. 1.

DIARIO OFICIAL DE LA FEDERACIÓN. Órgano del Gobierno Constitucional de los Estados Unidos Mexicanos. 2008, t. DCLVII, núm. 13.

DIARIO OFICIAL DE LA FEDERACIÓN. Órgano del Gobierno Constitucional de los Estados Unidos Mexicanos, 2009, t. DCLXIV, núm. 1.

DwOrkin, Ronald. 2004. Democracia deliberativa y derechos humanos, Barcelona, Gedisa.

Dye, Thomas y Zeigler, Harmon. 1997. "The Irony of Democracy", en Etzioni-Halevy, Eva (ed.), Classes and Elites in Democracy and Democratization: a Collection of Readings, Nueva York y Londres, Garland Publishinh Inc.

El Mundo InTERnaCional. 2016. "Amputan las manos a siete ladrones en México", disponible en: http://wrere.elmundo.es/internacional/2016/10 /18/58061152468aebe4138b4644.html.

Esta obra está bajo una Licencia Creative Commons

Atribución-NoComercial-SinDerivar 4.0 Internacional, IIJ-UNAM.

Boletín Mexicano de Derecho Comparado, núm. 157, enero-abril de 2020, pp. 243-270. 
EXCÉLSIOR. 2016. "Asesinados en La Marquesa asaltaban con frecuencia: transportistas", disponible en: http://wrere.excelsior.com.mx/comunidad/2016/11/01/1125583.

GARZÓN VALDÉS, Ernesto. 1993. "Acerca de los conceptos de publicidad, opinión pública, opinión de la mayoría y sus relaciones recíprocas", Doxa, Alicante, Área de Filosofía del Derecho, núm. 14.

GARZÓN VALDÉS, Ernesto. 2000. "El consenso democrático: fundamento y límites del papel de las minorías", Isonomía. Revista de Teoría y Filosofia del Derecho, núm. 12.

GARZÓN VALDÉS, Ernesto. 2003. "Algunas consideraciones sobre la posibilidad de asegurar la vigencia del «coto vedado» a nivel internacional", Derechos y Libertades. Revista del Instituto de Derechos Humanos Bartolomé de las Casas, año 8, núm. 12.

Hernández TerÁN, Miguel. 2015. El derecho constitucional a la resistencia. ¿Realidad o utopia??, Bogotá, Ediciones Jurídicas Gustavo Ibáñez.

HobBes, Thomas. 1651. "Leviathan or the Matter forme, \& Power of a Commonwealth Ecclesiastical and Civil”, impreso por Andrew Crook, The Green Dragon, St. Paul's Churchyard.

instituto de Defensa Legal. Centro de Promoción Social para LA SEguridad CiUdadana. 2003. Proyectos piloto de comités para la seguridad ciudadana. El ABC de la seguridad ciudadana, Lima, Instituto de Defensa Legal.

Instituto Federal Electoral (IFE). 2013. "Estudio censal de la participación ciudadana en las elecciones federales de 2012", disponible en: http://wrere.ine.mx/docs/IFE-v2/DECEYEC/DECEYEC-EstudiosInvestigaciones/InvestigacionIFE/Estudio_Censal_Participacion_Ciudadana_2012.pdf.

Instituto Nacional DE Estadística y GeOgRAFÍA (INEGI). 2017. "Seguridad pública y justicia", disponible en: http://wrwr.beta.inegi.org. mx/temas/incidencia/.

Instituto Nacional Electoral. 2015. "Informe país sobre la calidad de la ciudadanía en México", disponible en: http://wrwre.ine.mx/ archivos2/s/DECEYEC/EducacionCivica/Resumen_Ejecutivo_23nov.pdf.

MASSÉ NARVÁEZ, Carlos. 2007. "El mito del desarrollo latinoamericano", Revista de Antropología Experimental, núm. 7. 
MujICA, Pedro. 2008. "El concepto de participación ciudadana y su aplicación en las políticas públicas", Manual de participación ciudadana. Corporación Participa, Santiago, Editorial Paz Valenzuela.

NinO, Carlos Santiago. 2003. La constitución de la democracia deliberativa, Barcelona, Gedisa.

Ovejero Lucas, Félix. 2002. "Teorías y fundamentaciones de la democracia”, en HeRnÁNDEZ, Andrés (comp.), Republicanismo contemporáneo: igualdad, democracia deliberativa y ciudadana, Colombia, Universidad de los Andes.

PAz GonzÁlez, Isaac de. 2016. Constitucionalismo y justiciabilidad de los derechos sociales. Estudio comparado internacional y leading cases a través del juicio de amparo en México, México, Porrúa,

RuIZ, José Fabián. 2013. “¿Por qué prevalece el Estado de derecho? Una aproximación comparada a las explicaciones centradas en la cultura de la legalidad", Boletín Mexicano de Derecho Comparado, 46(136).

UniVisión Noticias. 2017. "Autodefensas en México se extienden: controlan 28 municipios de Michoacán", disponible en: http://wrwre. univision.com/noticias/noticias-de-mexico/autodefensas-en-mexico-se-extiendencontrolan-28-municipios-de-michoacan.

Valencia Villa, Hernando. 2014. Cartas de batalla. Una crítica del constitucionalismo colombiano, Bogotá, Panamericana Editorial-Agenda de Hoy.

Younes Moreno, Diego. 2004. Derecho constitucional colombiano, Bogotá, Ediciones Jurídicas Gustavo Ibáñez. 